\title{
Surface Studies and Implanted Helium Measurements Following NOVA High-Yield DT Experiments
}

\author{
M.A. Stoyer \\ G.B. Hudson
}

February 18, 1997

This is an informal report intended primarily for internal or limited external distribution. The opinions and conclusions stated are those of the author and may or may not be those of the Laboratory. 


\section{DISCLAIMER}

This document was prepared as an account of work sponsored by an agency of the United States Government. Neither the United States Government nor the University of California nor any of their employees, makes any warranty, express or implied, or assumes any legal liability or responsibility for the accuracy, completeness, or usefulness of any information, apparatus, product, or process disclosed, or represents that its use would not infringe privately owned rights. Reference herein to any specific commercial products, process, or service by trade name, trademark, manufacturer, or otherwise, does not necessarily constitute or imply its endorsement, recommendation, or favoring by the United States Government or the University or California. The views and opinions of authors expressed herein do not necessarily state or reflect those of the United States Government or the University of California, and shall not be used for advertising or product endorsement purposes.

This report has been reproduced directly from the best available copy.

Available to DOE and DOE contractors from the Onice of Scientific and Technical Information

P.O. Box 62, Oak Ridge, TN 37831

Prices available from (615) 576-8401, FTS 626-8401

A vailable to the public from the

National Technical Information Service

US. Department of Commerce

5285 Port Royal Rd.

Springfield, VA 22161 


\title{
Surface Studies and Implanted Helium Measurements Following NOVA High-Yield DT Experiments
}

\author{
February 18, 1997 \\ M.A. Stoyer and G.B. Hudson \\ Lawrence Livermore National Laboratory, \\ Livermore, CA 94550
}

\begin{abstract}
This paper presents the results of three March 6, 1996 direct-drive highyield DT NOVA experiments and provides 'proof-of-principal' results for the quantitative measurement of energetic He ions. Semiconductor quality $\mathrm{Si}$ wafers and an amorphous carbon wafer were exposed to NOVA high-yield implosions. Surface damage was sub-micron in general, although the surface ablation was slightly greater for the carbon wafer than for the Si wafers. Melting of a thin $(\sim 0.1 \mu)$ layer of $\mathrm{Si}$ was evident from microscopic investigation. Electron microscopy indicated melted blobs of many different metals (e.g. Al, $\mathrm{Au}, \mathrm{Ta}, \mathrm{Fe}$ alloys, $\mathrm{Cu}$ and even $\mathrm{Cd}$ ) on the surfaces. The yield measured by determining the numbers of atoms of implanted ${ }^{4} \mathrm{He}$ and ${ }^{3} \mathrm{He}$ indicate the number of DT fusions to be $9.1( \pm 2.3) \times 10^{12}$ and DD fusions to be $4.8( \pm 1.0) \times 10^{10}$ respectively. The helium DT fusion yield is slightly lower than that of the $\mathrm{Cu}$ activation measurement, which was $1.3( \pm 0.1) \times 10^{13} \mathrm{DT}$ fusions.
\end{abstract}

\section{INTRODUCTION}

The Isotope Sciences Division of Lawrence Livermore National Laboratory is applying the expertise of over 40 years of radiochemical diagnostics in the nuclear test program to the Inertial Confinement Fusion (ICF) effort in Lasers Program. Development of radiochemical diagnostics for the National Ignition Facility (NIF) is under way. Some diagnostic ideas can be tested at NOVA. One of the interesting diagnostics of an ICF implosion is the density achieved in 
the target capsule. The density can be measured a variety of ways, but charged particle measurements potentially offer a sensitive technique for diagnosing the implosion. This paper presents the results of our first NOVA tests investigating surface ablation effects and measurement of the direct fusion products $\left({ }^{3} \mathrm{He}\right.$ and ${ }^{4} \mathrm{He}$ ) using helium implantation.

\section{EXPERIMENTAL DETAILS}

To investigate the amount of surface ablation, semiconductor quality $\mathrm{Si}$ wafers and an amorphous carbon wafer were exposed to NOVA high yield DT experiments on March 6, 1996. The target dimensions, DT fill pressures, and $\mathrm{SiO}_{2}$ glass trace impurities for each capsule used in these experiments are indicated in Table 1. The wafers were perpendicular to the target and positioned $20 \mathrm{~cm}$ from the target using SIMS cart \#3 in the NOVA 10-beam target chamber. The wafers exposed, configuration for each experiment, and yield from $\mathrm{Cu}$ activation are indicated in Table 2. Optical microscopy and electron microscopy were used to study the exposed surfaces. Measurements of surface roughness were made with a SLOAN DEKTAK II.

On the third high yield experiment, helium isotopes were measured using noble gas mass spectrometry [1]. Both ${ }^{4} \mathrm{He}$ and ${ }^{3} \mathrm{He}$ were measured. Helium was released from the samples using vacuum pyrolysis. A schematic diagram of the all-metal gas liberation and purification system is shown in Figure 1. 
Energetic helium ions implanted into the Si wafers are expected to be quantitatively retained at room temperature for long periods. Natural silicate minerals retain alpha decay $\left({ }^{4} \mathrm{He}\right)$ products for millions of years at room temperatures. We expect to be able to quantitatively liberate this trapped He by heating the sample to temperatures above $1000^{\circ} \mathrm{C}$. Two different high-temperature crucibles were used for this study. For the first sample, designated Si-3D, a stainless steel tube was heated using an external resistance heater. The maximum temperature for this crucible was $1000^{\circ} \mathrm{C}$. For the 2nd and 3rd samples, we used a Mo crucible and a Mo resistance heating element both inside a vacuum jacket. This crucible system was able to reach temperatures of $1750^{\circ} \mathrm{C}$.

For analysis, samples were loaded one at a time into the crucible and evacuated to approximately $10^{-8}$ torr. Gas was extracted from the sample in multiple steps. The first step was without heating the sample to measure the system background and verify that the system was fully leak-free. The sample was then repeatedly heated to either $1000^{\circ} \mathrm{C}$ (for the first sample) or $1250^{\circ} \mathrm{C}$ (for the 2nd and 3rd samples). Only the first heating at $1000^{\circ} \mathrm{C}$ or $1250^{\circ} \mathrm{C}$ showed significant ${ }^{3} \mathrm{He}$ and ${ }^{4} \mathrm{He}$ amounts as compared to system background, indicating that the first heating in all cases was sufficient to release the implanted He. The heating duration was 15 minutes. After 5 minutes of cooling, the gases were exposed to a hot Ti-alloy getter (SAES 172 material at $250^{\circ} \mathrm{C}$ ) for 5 minutes which quantitatively removed all gas species but the noble gases. 
The gases were then exposed to activated charcoal at $77 \mathrm{~K}$ in two stages for a total of 5 minutes. At this point only He and $\mathrm{Ne}$ remain in the gas phase. The He and Ne were then quantitatively collected on activated charcoal at 15K. The final section of the sample manifold was then isolated and the final charcoal trap temperature was raised to $40 \mathrm{~K}$ releasing the He. The mass spectrometer pump valves were then closed and the sample He was admitted to the mass spectrometer for analysis.

The mass spectrometer is a VG-5400 noble gas mass spectrometer operated at a mass resolving power of approximately 600 . At this resolving power, ${ }^{3} \mathrm{He}$ is completely separated from $\mathrm{HD}$ and $\mathrm{H}_{3}$ molecules. Ions are produced by electron bombardment and are accelerated to $5 \mathrm{kV}$ and mass separated in a sector magnetic field (12 inch effective radius). Ions are detected using an electron multiplier operated at high-gain in a pulse-counting mode. Instrument sensitivity is calibrated using known amounts of air $\left(6.84 \times 10^{10}\right.$ atoms ${ }^{4} \mathrm{He}$ and $9.46 \times 10^{4}$ atoms ${ }^{3} \mathrm{He}$ ). The instrument response was stable at $1.05 \times 10^{5}$ atoms $/($ counts $/ \mathrm{sec})$ during the analysis period. The sensitivity of ${ }^{3} \mathrm{He}$ and ${ }^{4} \mathrm{He}$ were the same. This calibration is accurate to approximately $10 \%$. These measurements were not sensitivity limited, system backgrounds of ${ }^{3} \mathrm{He}$ and especially ${ }^{4} \mathrm{He}$ represent the limiting factors. System backgrounds were estimated in a variety of ways. Numerous analysis were performed without a sample being present, also analysis before and after this first high-temperature 
step give indications of the size of the background. Based on our background measurements, about $21 \%$ of the ${ }^{4} \mathrm{He}$ sample signal was due to background ${ }^{4} \mathrm{He}$ and about $2 \%$ of the ${ }^{3} \mathrm{He}$ sample signal was due to background signal. In general the ${ }^{3} \mathrm{He}$ background is much lower than the ${ }^{4} \mathrm{He}$ background and this presumably is related to the atmospheric He isotope abundance ratio, ${ }^{3} \mathrm{He} /{ }^{4} \mathrm{He}=1.384 \times 10^{-6}$.

\section{RESULTS AND DISCUSSION}

\section{A. Microscopy}

Surface profiling indicated the amount of ablation on average was submicron for both the Si and carbon. Pits up to $1-1.5 \mu$ were observed on both the $\mathrm{Si}$ and carbon. The average roughness and the amount of ablation on the amorphous carbon was greater than on the Si. The carbon wafer ablated on average a depth of approximately $0.2 \mu$ while the $\mathrm{Si}$ wafers had an average ablation depth of $0.05 \mu$. The average roughness of exposed surfaces was ten times that of the unexposed surfaces. A typical surface profile is shown in Figure 2 for a $\mathrm{Si}$ wafer from the second experiment. Note the ridge of material that is $1 \mu$ high at the edge of the exposed surface. Optical microscopy indicated many features on the surfaces that were exposed, including melting, impact craters, spraying of melted material, pitting, and blobs of melted material deposited on the surface. A Si wafer sustained at least three waves 
of melting or ripples near the edge of the exposed portion of the wafer (see Figure 3). The lower yield experiments had more large fragments, whereas the higher yield experiment had smaller fragments and more melting. Electron microscopy identified $\mathrm{Al}, \mathrm{Ta}, \mathrm{Au}, \mathrm{Fe}$ alloys, alumina silicates, $\mathrm{Cu}$ and even Cd blobs of $1-10 \mu$ size (see Figure 4). These experiments were direct drive experiments and therefore there was no Au hohlraum present; however, there were hohlraum experiments earlier in the day and hence cross-contamination is observed between experiments.

\section{B. Helium Measurements}

Because the wafers subtended a small solid angle in these experiments, helium analysis was only attempted for the highest yield experiment. Four wafers were exposed in this experiment. The results of the helium measurements for three of the wafers are shown in Table 3 . The ${ }^{3} \mathrm{He}$ measured determines the DD fusion rate and the ${ }^{4} \mathrm{He}$ measured determines the DT fusion rate. These measurements assume no loss of helium in the target capsule and $100 \%$ collection/implantation efficiency. The wafers were much thicker than the range of the helium particles. It should be noted that tritium initially in the target capsule that is not burned up in the implosion and not removed from the target chamber contributes a background to the ${ }^{3} \mathrm{He}$ measurement. The contribution to the ${ }^{3} \mathrm{He}$ signal in this experiment from this residual tritium is estimated to 
be less than $1 \%$. The uncertainties in this 'proof-of-principal' experiment are higher than can be obtained in future experiments. Increasing the solid angle subtended in these experiments will significantly reduce the uncertainties due to mass spectrometer backgrounds. It is expected that the total uncertainty would be less than $5 \%$ in an experiment with larger solid angle coverage. The measured yield for this experiment from the helium measurements and $\mathrm{Cu}$ activation (the standard NOVA yield determinant) is shown in Table 4. The ${ }^{4} \mathrm{He}$ measurement indicates a slightly lower, though reasonably consistent, yield than the $\mathrm{Cu}$ activation. The NOVA neutron time-of-flight (TOF) diagnostic also indicated a slightly lower yield of $9.53( \pm 0.006) \times 10^{12}$ fusions. The error on the neutron TOF yield is statistical only as systematic errors are difficult to estimate.

The ${ }^{3} \mathrm{He} /{ }^{4} \mathrm{He}$ ratio as a function of temperature is shown in Figure 5[2]. The measured ${ }^{3} \mathrm{He} /{ }^{4} \mathrm{He}$ ratio of $0.0027 \pm 0.0005$ is lower than the ratios shown in Figure 5, perhaps indicating a loss of ${ }^{3} \mathrm{He}$, which is produced in DD fusion with much lower energy than the $\alpha$-particles produced in DT fusion. These lower energy ${ }^{3} \mathrm{He}$ particles are not implanted as deeply as the ${ }^{4} \mathrm{He}$, and also are more susceptible to energy loss in the plasma. Future experiments will examine this effect carefully to evaluate whether the low ${ }^{3} \mathrm{He}$ value represents the ion energy loss in the explosion plasma. 


\section{CONCLUSIONS}

Semiconductor quality Si wafers and an amorphous carbon wafer when exposed to NOVA high-y:eld implosions incurred surface damage that was sub-micron in general, although ablation and surface roughness was slightly higher for the carbon wafer than for the Si wafers. The fusion yield measured by determining the amount of ${ }^{4} \mathrm{He}$ and ${ }^{3} \mathrm{He}$ indicated the number of DT fusions to be $9.1( \pm 2.3) \times 10^{12}$ and $\mathrm{DD}$ fusions to be $4.8( \pm 1.0) \times 10^{10}$, respectively. It should be noted that the DD fusion rate is not routinely measured in these experiments. The helium DT fusion yield was slightly lower than that of the $\mathrm{Cu}$ activation measurement, which was $1.3( \pm 0.1) \times 10^{13} \mathrm{DT}$ fusions. It remains to be investigated as to whether the lower helium measurements are because of energy loss in the implosion or just statistics. Nevertheless, one can see that this helium measurement technique may be useful in determining the fusion rates as well as potentially measuring He ion energy losses travelling out of the

explosion plasma. Future experiments using stacked thin foils may be able to measure the energy spectrum of ${ }^{3} \mathrm{He},{ }^{4} \mathrm{He}$ and ${ }^{3} \mathrm{H}$ emitted from the plasma.

\section{ACKNOWLEDGEMENTS}

The LLNL research effort is supported by the Director, Office of Energy Research, Division of Nuclear Physics of the US Department of Energy under contract No. W-7405-ENG-48. We would like to acknowledge Mike Nelson, 
Craig Sangster and Tom Phillips of the NIF Diagnostics group for their help in performing this experiment. We would also like to acknowledge Doug Phinney for supplying the $\mathrm{Si}$ and carbon wafers and help with the optical microscopy analysis, Ian Hutcheon for the electron microscopy work, and Ron Lougheed for valuable discussions. 


\section{References}

[1] C.M. Hohenberg Rev. Sci. Inst. 51 (1980) 1075.

[2] S.L. Greene, UCRL-70522 (1967). 


\section{TABLES}

Table 1: Composition of NOVA target capsules.

\begin{tabular}{|c|c|c|c|}
\hline Experiment & Capsule Size $(\mu)$ & Shell Thickness $(\mu)^{*}$ & D/T Fill (atm) \\
\hline 1 & 1313 & 3.1 & 20 \\
2 & 1338 & 3.2 & 20 \\
3 & 1344 & 3.2 & 20 \\
\hline
\end{tabular}

* Composition of shell was $95.8 \% \mathrm{SiO}_{2}, 2.0 \% \mathrm{Rb}_{2} \mathrm{O}, 1.4 \% \mathrm{Na}_{2} \mathrm{O}$, and $0.7 \% \mathrm{~K}_{2} \mathrm{O}$.

Table 2: Configuration of exposed wafers during three NOVA experiments.

\begin{tabular}{|c|c|c|c|c|}
\hline $\begin{array}{c}\text { Experiment } \\
\text { No. }\end{array}$ & Wafers & $\begin{array}{c}\text { Exposure Size } \\
\left(\mathrm{cm}^{2}\right)\end{array}$ & Laser Freq. & $\begin{array}{c}\text { Yield } \\
\text { (DT fusions) }\end{array}$ \\
\hline 1 & $\mathrm{Si}$ & 1.6 & $2 \omega$ & $1.3( \pm 0.2) \times 10^{12}$ \\
1 & $\mathrm{C}$ & 1.6 & $2 \omega$ & $1.3( \pm 0.2) \times 10^{12}$ \\
2 & $\mathrm{Si}$ & $2.4-\cdot$ & $2 \omega$ & $2.0( \pm 1.1) \times 10^{12}$ \\
3 & $\mathrm{Si}$ & 3.2 & $3 \omega$ & $1.3( \pm 0.1) \times 10^{13}$ \\
\hline
\end{tabular}

* From $\mathrm{Cu}$ activation. 
Table 3: Total helium atoms produced in third high-yield experiment.

\begin{tabular}{|c|c|c|c|}
\hline Si Wafer & ${ }^{4} \mathrm{He}$ (atoms) & ${ }^{3} \mathrm{He}$ (atoms) & ${ }^{3} \mathrm{He} /{ }^{4} \mathrm{He}$ \\
\hline A & $7.6 \times 10^{12}$ & $2.4 \times 10^{10}$ & 0.0032 \\
C & $8.9 \times 10^{12}$ & $2.3 \times 10^{10}$ & 0.0025 \\
D & $1.1 \times 10^{13}$ & $2.5 \times 10^{10}$ & 0.0023 \\
\hline Average & $9.1 \times 10^{12}$ & $2.4 \times 10^{10}$ & 0.0027 \\
Standard Deviation & $17 \%$ & $5 \%$ & $17 \%$ \\
Total Uncertainty & $25 \%$ & $21 \%$ & $14 \%$ \\
\hline
\end{tabular}

* Corrected for background by $\sim 21 \%$.

$t$ Corrected for background by $\sim 1.8 \%$.

Table 4: Measured yield for third experiment.

\begin{tabular}{|c|c|c|c|}
\hline Method & Type & Yield & Error \\
\hline TOF & DT & $9.5 \times 10^{12}$ & $0.1 \%^{*}$ \\
Cu activation & DT & $1.3 \times 10^{13}$ & $7 \%$ \\
${ }^{4} \mathrm{He}$ & DT & $9.1 \times 10^{12}$ & $25 \%$ \\
${ }^{3} \mathrm{He}$ & DD & $4.8 \times 10^{10}$ & $20 \%$ \\
\hline
\end{tabular}

* Statistical only, systematic errors large and difficult to estimate. 


\section{FIGURES}

\section{Gas Handling System for He Analysis}

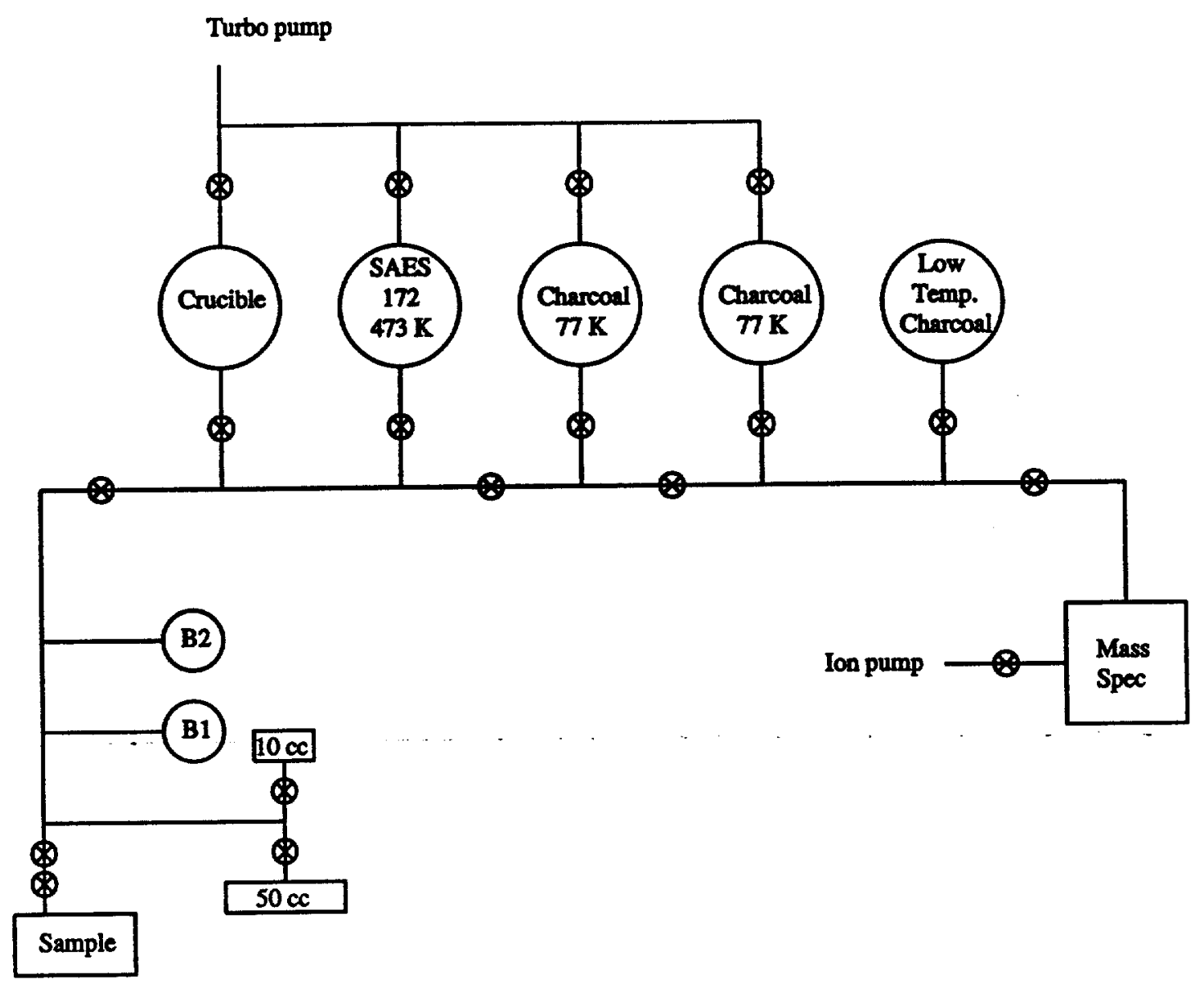

Figure 1: Schematic diagram of the liberation and purification apparatus for the helium measurements. Circles with " $\mathrm{X}$ " indicate valves. B1 and B2 are high-accuracy, capacitive manometer pressure gauges and when coupled with the precise $10 \mathrm{cc}$ or $50 \mathrm{cc}$ volumes can be used for accurate determination of air calibration sample size. The operation of the apparatus is described in the text. 


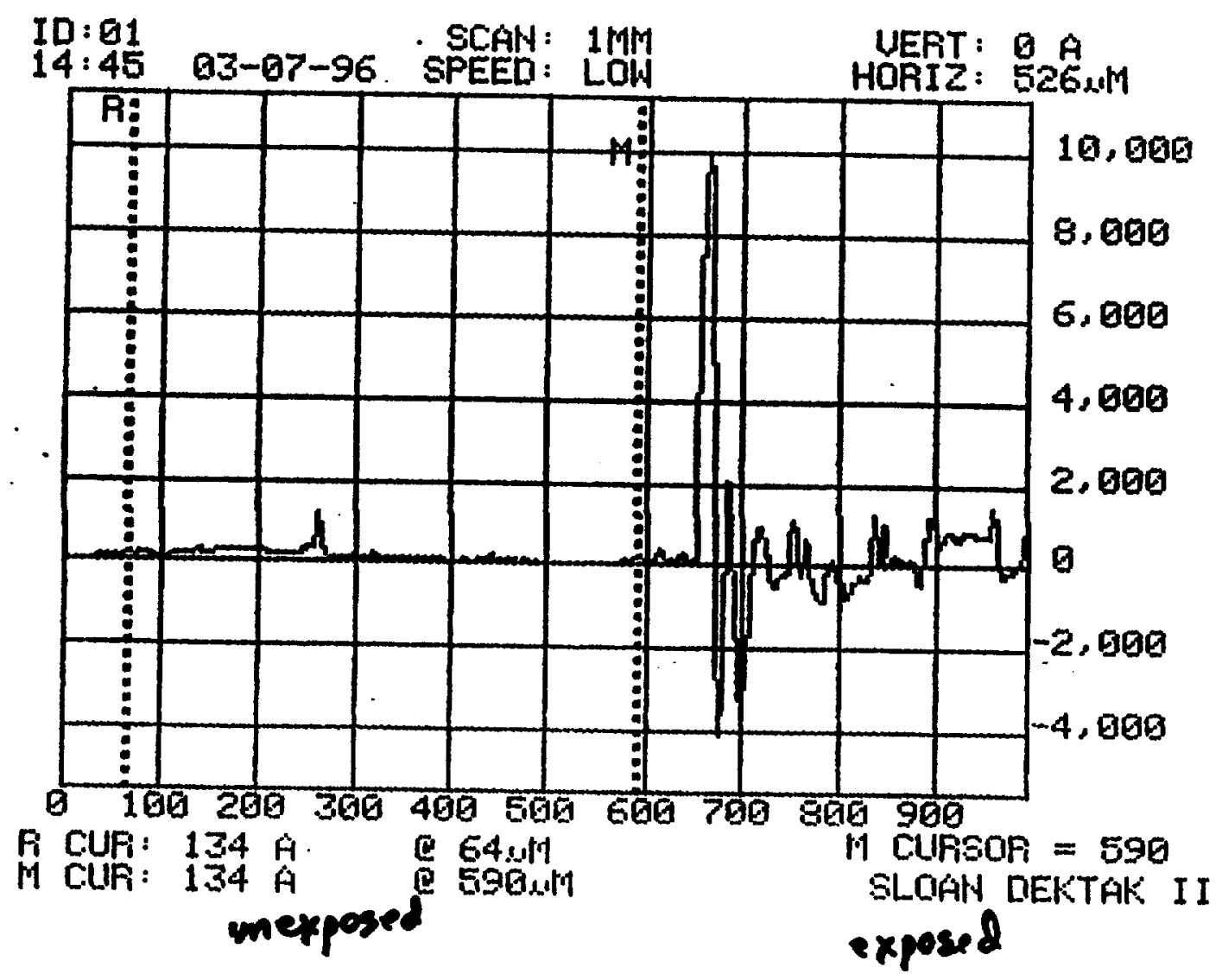

Figure 2: SLOAN DEKTAK II trace of Si wafer that was exposed in the second experiment. The length of surface profiled was $1 \mathrm{~mm}$, and the vertical depth scale was angstroms. Approximately half of the trace is for unexposed surface (as labelled). Note the $1 \mu$ ridge of material at the edge of the exposed $\mathrm{Si}$ surface. 


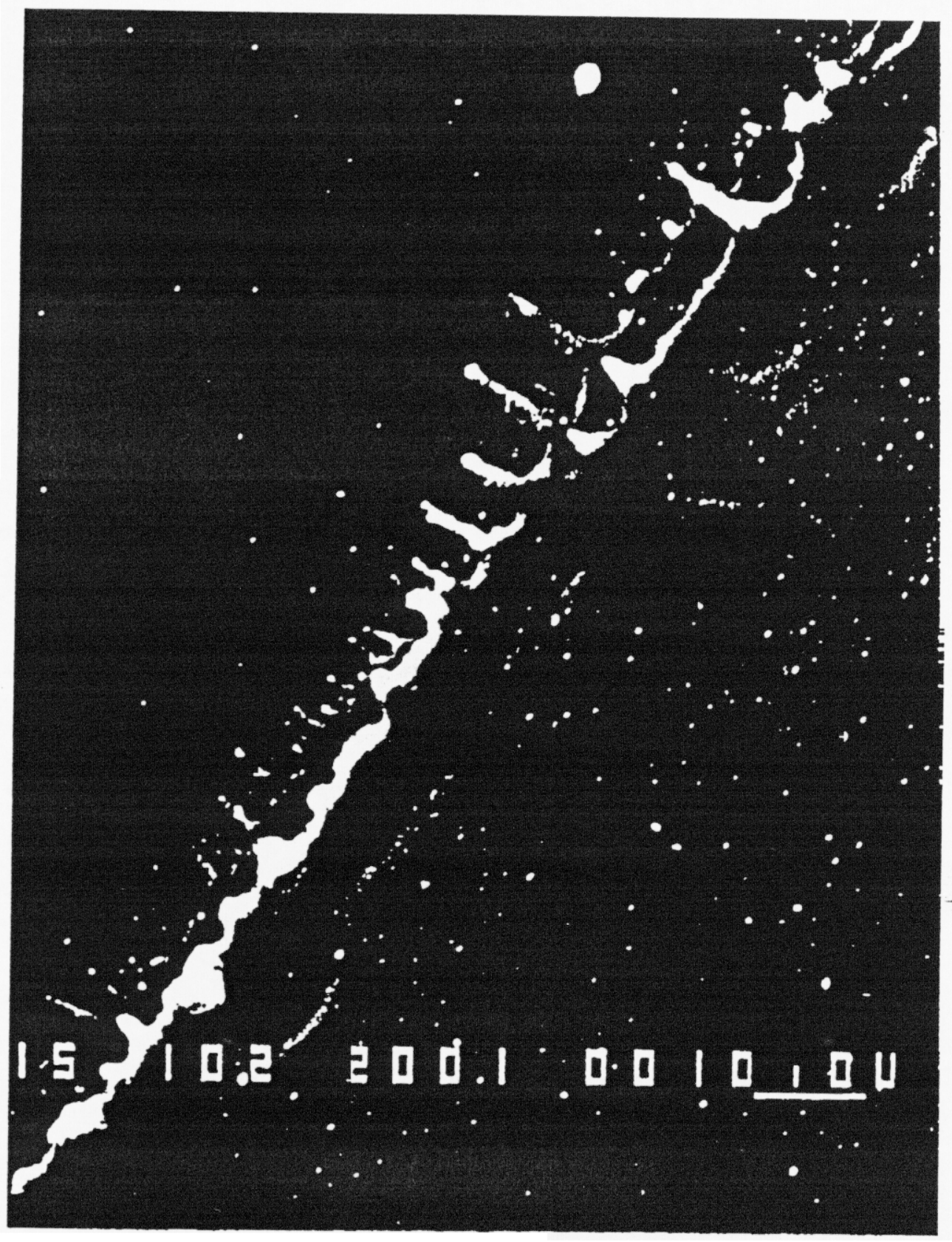

Figure 3: Electron microscope picture of a Si wafer showing several waves of melting at the edge of the exposed region. The bar at the lower right corner of the picture indicates the scale of $1 \mu$. 


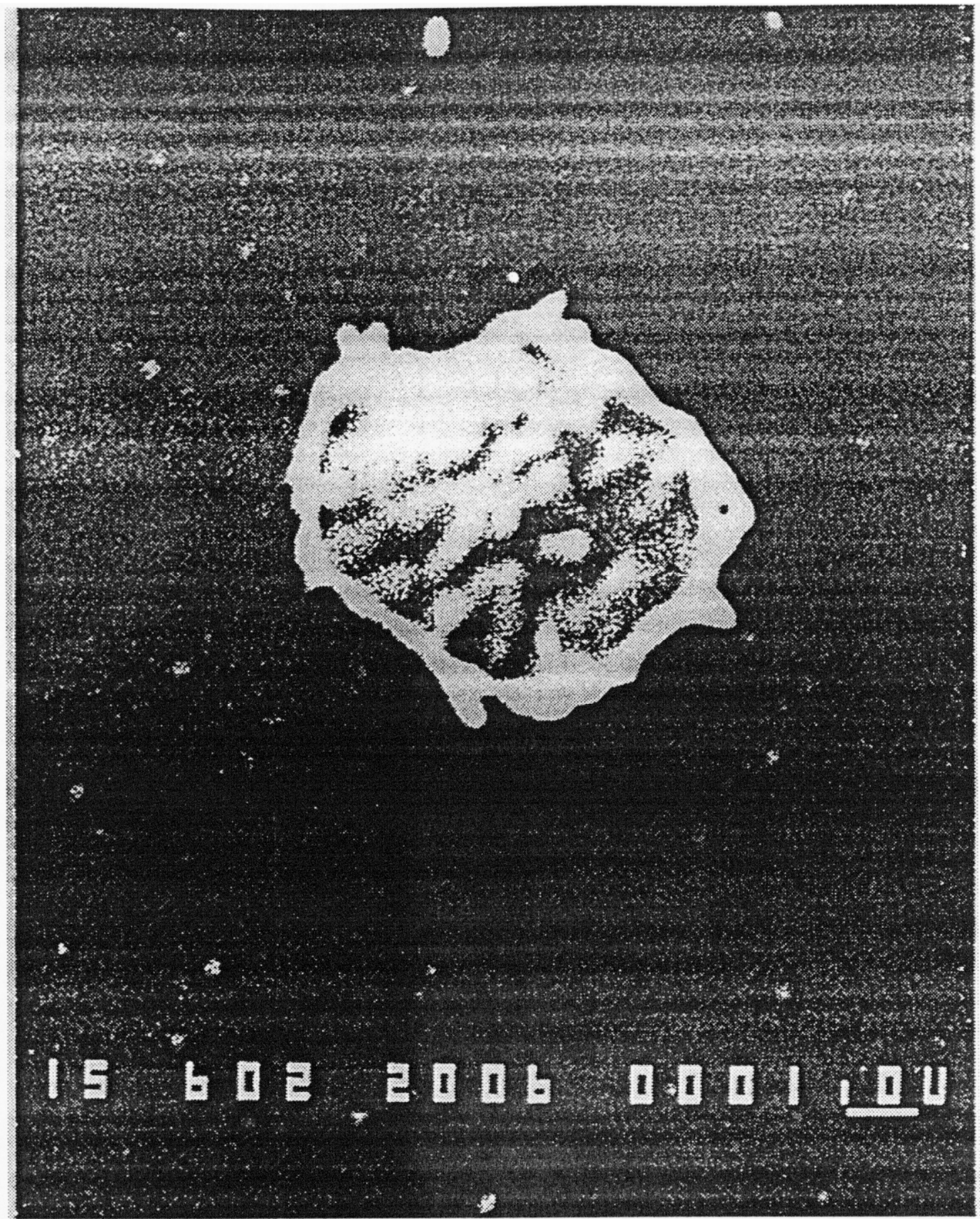

Figure 4: Electron microscope picture of a Si wafer. The irregular blob is Cd. The bar at the lower right corner of the picture indicates the scale of $1 \mu$. 


\section{Temperature Dependence of DD/DT Fusion Rates}

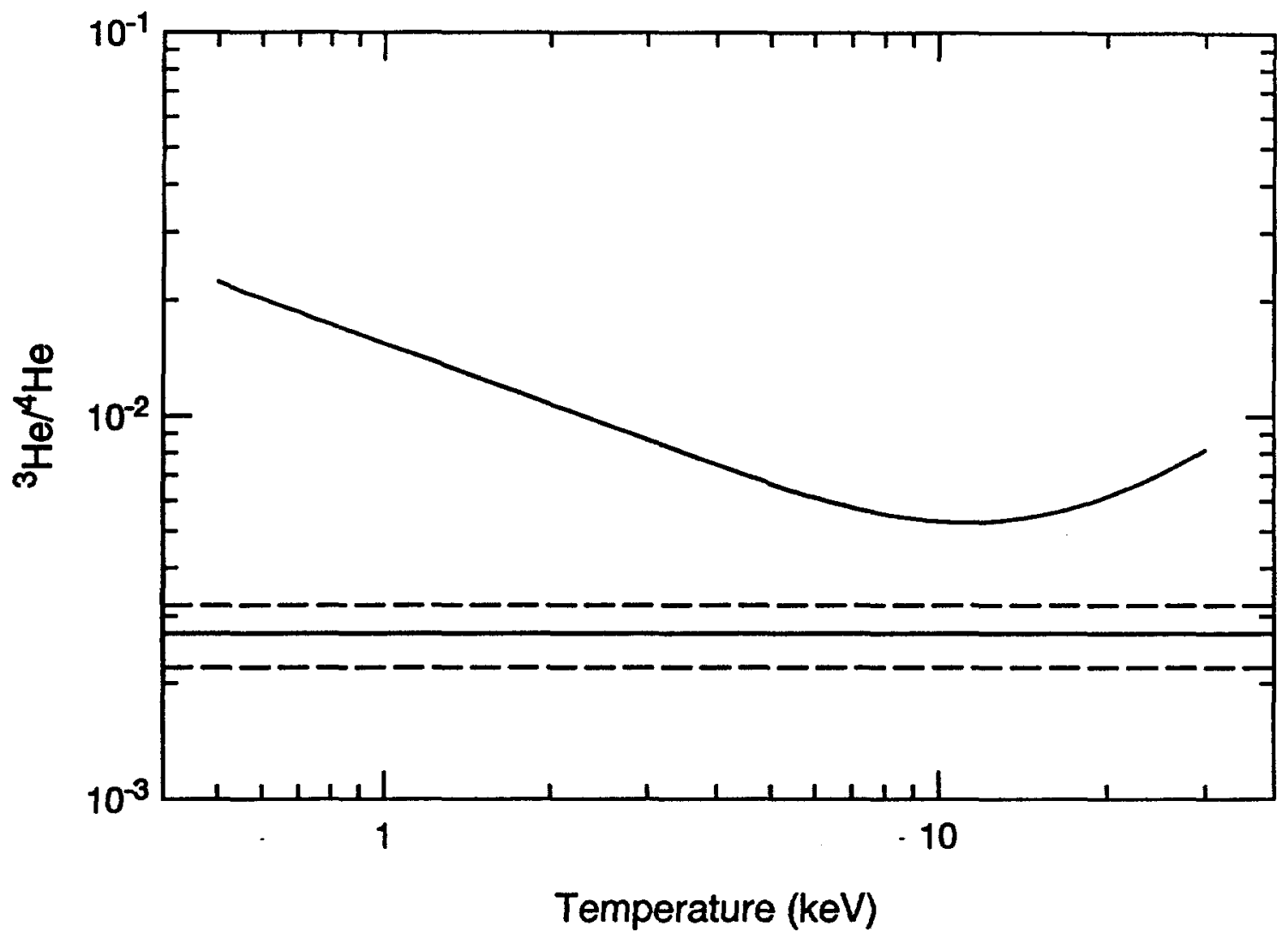

Figure 5: Fusion product ratio as a function of plasma temperature. The horizontal line indicates the ${ }^{3} \mathrm{He} /{ }^{4} \mathrm{He}$ ratio measured in the third experiment, with the dashed lines indicating $1 \sigma$ errors. The ${ }^{3} \mathrm{He}$ was possibly lost during implantation in this experiment. 


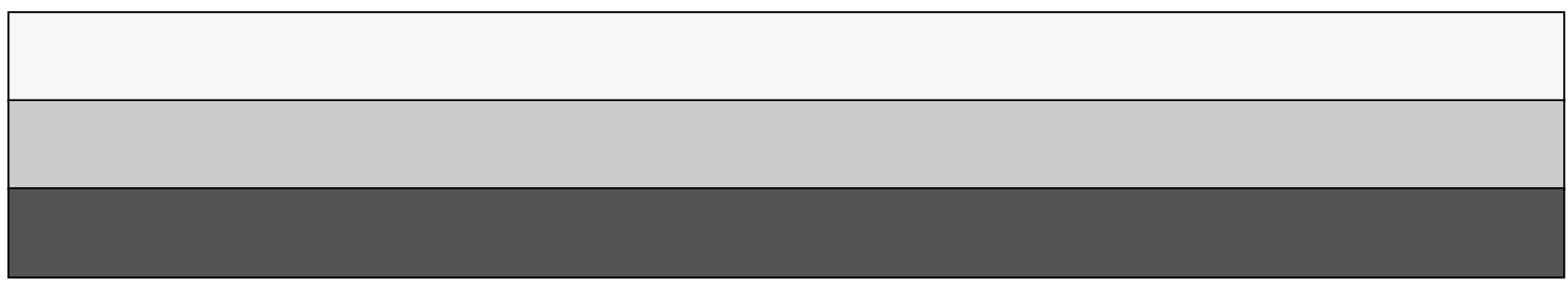

